\title{
Nondegenerate Optical Parametric Chirped Pulse Amplification
}

I. Jovanovic, C.A. Ebbers, B.C. Stuart, M.R. Hermann, E.C. Morse

This article was submitted to 2002 CLEO/QELS Conference on Lasers and Electro-Optics Quantum Electronics and Lasers, Long Beach, CA, May 19-21, 2002

\section{November 7, 2001}

Lawrence

Livermore

National

Laboratory 


\section{DISCLAIMER}

This document was prepared as an account of work sponsored by an agency of the United States Government. Neither the United States Government nor the University of California nor any of their employees, makes any warranty, express or implied, or assumes any legal liability or responsibility for the accuracy, completeness, or usefulness of any information, apparatus, product, or process disclosed, or represents that its use would not infringe privately owned rights. Reference herein to any specific commercial product, process, or service by trade name, trademark, manufacturer, or otherwise, does not necessarily constitute or imply its endorsement, recommendation, or favoring by the United States Government or the University of California. The views and opinions of authors expressed herein do not necessarily state or reflect those of the United States Government or the University of California, and shall not be used for advertising or product endorsement purposes.

This is a preprint of a paper intended for publication in a journal or proceedings. Since changes may be made before publication, this preprint is made available with the understanding that it will not be cited or reproduced without the permission of the author.

This report has been reproduced directly from the best available copy.

Available electronically at http://www.doe.gov/bridge

Available for a processing fee to U.S. Department of Energy

and its contractors in paper from

U.S. Department of Energy

Office of Scientific and Technical Information

P.O. Box 62

Oak Ridge, TN 37831-0062

Telephone: (865) 576-8401

Facsimile: (865) 576-5728

E-mail: reports@adonis.osti.gov

Available for the sale to the public from

U.S. Department of Commerce

National Technical Information Service

5285 Port Royal Road

Springfield, VA 22161

Telephone: (800) 553-6847

Facsimile: (703) 605-6900

E-mail: orders@ntis.fedworld.gov

Online ordering: http://www.ntis.gov/ordering.htm

OR

Lawrence Livermore National Laboratory

Technical Information Department's Digital Library

http://www.llnl.gov/tid/Library.html 


\title{
Nondegenerate optical parametric chirped pulse amplification
}

\author{
Igor Jovanovic $^{1,2}$, Christopher A. Ebbers ${ }^{1}$, Brent C. Stuart ${ }^{1}$, Mark R. Hermann ${ }^{1}$, and E. C. Morse ${ }^{2}$ \\ ${ }^{\prime}$ Lawrence Livernore National Laboratory, Mail Code L-490, 7000 East Avenue, Livermore, California 94550 \\ ${ }^{2}$ Department of Nuclear Engineering, University of California at Berkeley, Berkeley, California 94720 \\ jovanovic1@llnl.gov
}

\begin{abstract}
We present the first recompression of amplified pulses in a highly nondegenerate optical parametric chirped pulse amplifier. 60 -fs recompressed pulse width and up to $2 \mathrm{~mJ}$ pulses were obtained in our experiments.

(C2001 Optical Society of America

OCIS codes: (190.4970) Parametric oscillators and amplifiers; (140.7090) Ultrafast lasers
\end{abstract}

Generation and amplification of ultrashort laser pulses has been at the forefront of laser research in the recent period, driven primarily by newly accessible physics phenomena and commercial applications such as materials processing. The interest in optical parametric chirped pulse amplification (OPCPA) [1] for ultrashort pulse amplification has been motivated by its favorable properties. Large single-pass gain achievable in a $\sim \mathrm{cm}$ length of nonlinear material pumped by nanosecond pump laser eliminates the need for regenerative amplification. Broad bandwidth capabilities and scalability make OPCPA a possible amplification technology for future multi-PW sources [2]. Absence of thermal load should allow short pulse amplification up to $\mathrm{kW}$-level average power. While the ultrashort amplification capabilities of optical parametric amplifiers (OPAs) have been demonstrated down to 5 fs, the compression of ultrashort ( $<100 \mathrm{fs}$ ) pulses in thick OPCPA crystals remains largely unexplored. Here, we present the first pulse compression in highly nondegenerate OPCPA and obtain the shortest pulses produced in OPCPA to date.

The design of our OPCPA system is presented in Fig. 1. A mode-locked oscillator, which produces 20 -fs pulses centered at $820 \mathrm{~nm}$, is used as a seed source. An all-reflective stretcher is used to stretch the seed pulses to 600 ps, with a spectral cut-off width in excess of $100 \mathrm{~nm}$. The OPA consists of two antireflection-coated beta-barium borate (BBO) crystals. The crystals are cut at $23.8^{\circ}$ to facilitate type I phase matching at an external noncollinear angle of $3.7^{\circ}$. The noncollinear angle is optimized numerically to maximize the gain bandwidth. The length of each crystal is $15 \mathrm{~mm}$, and they have a wedged output surface to eliminate parasitic oscillation. The pump beam is relay imaged between the two crystals and the beam diameter is adjusted to $3 \mathrm{~mm}$, for a peak intensity near $450 \mathrm{MW} / \mathrm{cm}^{2}$. We obtained a maximum gain of $4 \times 10^{6}$ from the OPA when the noncollinear plane was chosen to be perpendicular to the principal plane of the crystal. The result were pulses with energies of up to $2 \mathrm{~mJ}$ amplified in a single pass through only $30 \mathrm{~mm}$ of gain material. The measured seed and amplified signal spectra are shown in Fig 2 . We observe a shift of the center wavelength to $830 \mathrm{~nm}$, which is consistent with the gain bandwidth in nondegenerate BBO OPA, which is centered at longer wavelengths (near $850 \mathrm{~nm}$ ). The small bandwidth narrowing $(<2 \mathrm{~nm})$ at the FWHM observed when the OPA operates far below saturation $(0.5 \mathrm{~mJ})$ can be attributed to this spectral shift. At the point near saturation $(2 \mathrm{~mJ})$, the spectrum is modified further and the amplified FWHM is increased to $35 \mathrm{~nm}$. Spectral broadening is the result of different rate of nonlinear conversion for the spectral components of different initial intensity. We recompressed our pulses in a single-grating compressor, and the autocorrelation trace is shown in Fig. 3. The measured FWHM autocorrelation of the recompressed pulse is $104 \mathrm{fs}$, which is nearly 2 times longer than the FWHM of the calculated autocorrelation of the transform-limited pulse with the measured spectrum (Fig 2 ). With the inclusion of the spectral phase in the system, the calculated FWHM of the autocorrelation is 108 fs, which is within our experimental error, indicating that we produced 60 -fs pulses.

In summary, we report for the first time the compression of pulses amplified in nondegenerate OPCPA. The reported 60 -fs pulses are the shortest pulses reported to date produced in an OPCPA system. A careful compensation of spectral phase in our system should enable 30 -fs transform-limited pulses.

This work was performed under the auspices of the U. S. Department of Energy by Lawrence Livermore National Laboratory under Contract No. W-7405-Eng-48.

This work was performed under the auspices of the U.S. Department of Energy by the University of California, Lawrence Livermore National Laboratory under Contract No. W-7405-Eng-48. 


\section{References}

1. A. Dubietis, G. Jonusauskas, and A. Piskarskas, "Powerful femtosecond pulse generation by chirped and stretched pulse parametric amplification in BBO crystal," Opt. Commun. 88, 437-440 (1992).

2. I. N. Ross, P. Matousek, M. Towrie, A. J. Langley, J. L. Collier, 'The prospects for ultrashort pulse duration and ultrahigh intensity using optical parametric chirped pulse amplifiers" Opt. Commun. 144, 125 (1997). 


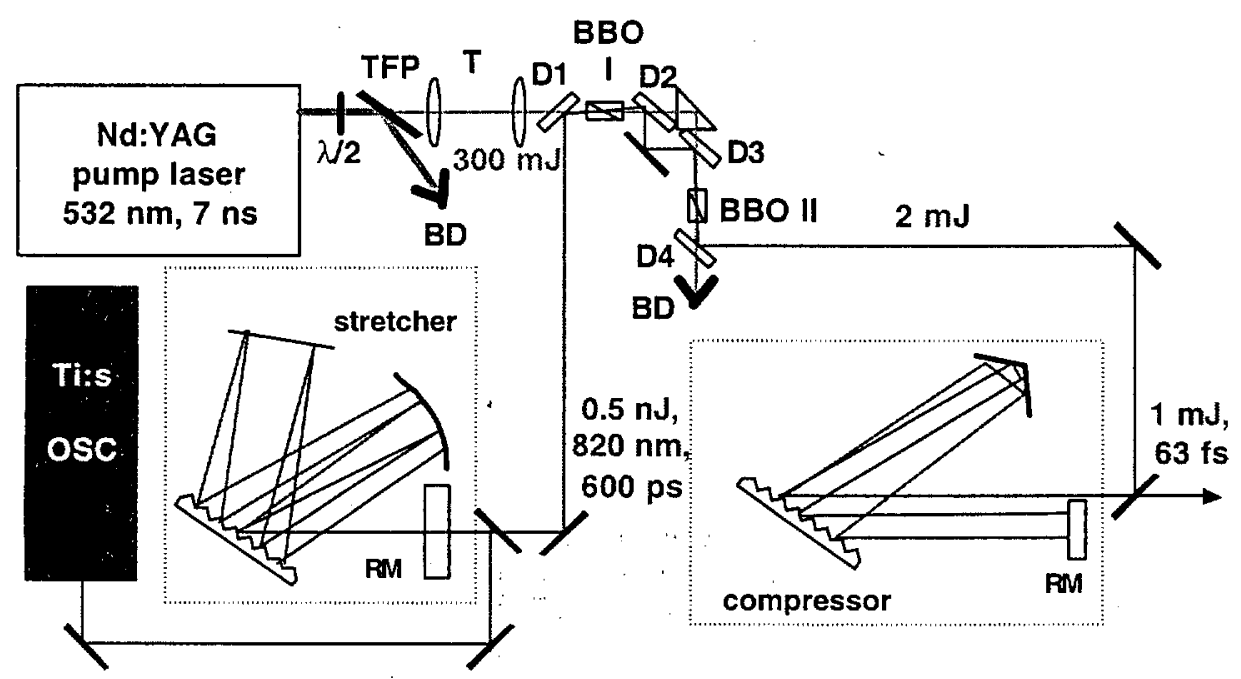

Fig. 1. Experimental setup. TFP-thin film polarizer, T-telescope, D-dichroic. $N 2$-waveplate, TFP-thin film polarizer, BD-beam dump, RM-roof mirror. 


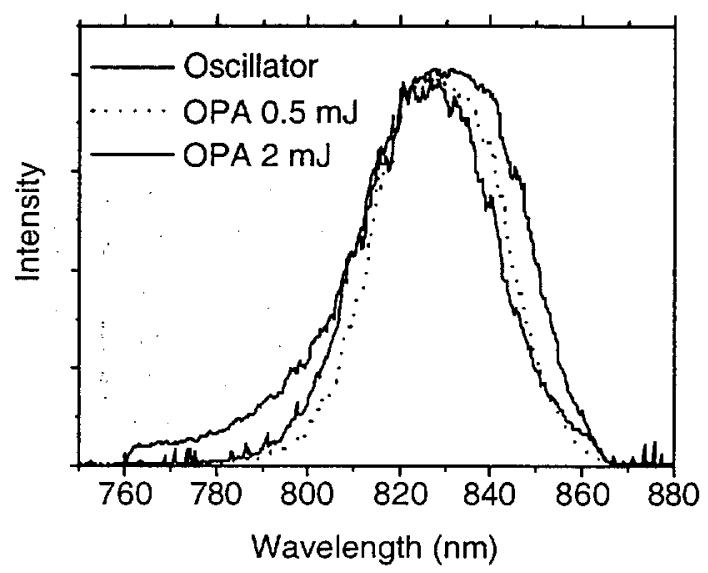

Fig. 2. Seed and amplified signal spectra from the nondegenerate OPCPA system 


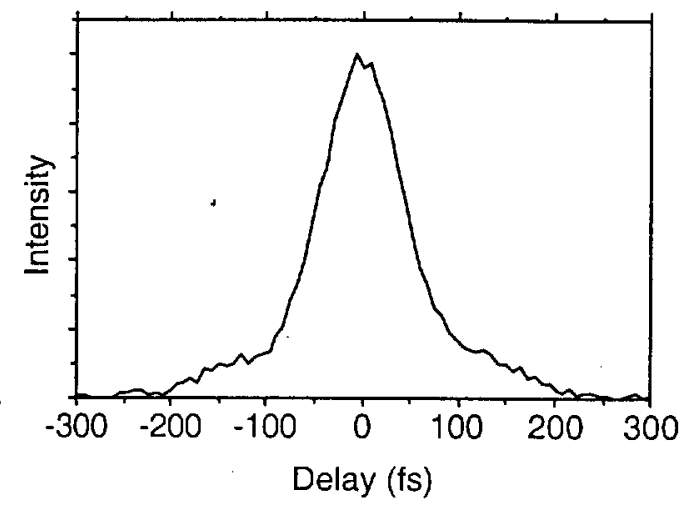

Fig.3. Recompressed pulse autocorrelation 